\title{
ASSESSING THE RELIABILITY OF SINGLE AND COMBINED DIAGNOSTIC TOOLS FOR TESTING THE MECHANICAL PROPERTIES OF HISTORIC MASONRY STRUCTURES
}

\author{
${ }^{1}$ Brigitta BALLA ${ }^{*}{ }^{2}$ Zoltán ORBÁN, ${ }^{3}$ Adél LEN \\ 1,2,3 Department of Civil Engineering, and Structural Diagnostics and Analysis Research Team \\ Institute of Smart Technology and Engineering, Faculty of Engineering and Information \\ Technology, University of Pécs, Boszorkány u. 2, H-7624 Pécs, Hungary \\ e-mail: ${ }^{1}$ torok.brigitta@witch.mik.pte.hu, ${ }^{2}$ orbanz@mik.pte.hu, ${ }^{3}$ len.adel@mik.pte.hu \\ ${ }^{3}$ Nuclear Analysis and Radiography Department, Hungarian Academy of Sciences \\ Center for Energy Research, Konkoly-Thege 29-33, Budapest, Hungary
}

Received 15 January 2019; accepted 3 May 2019

\begin{abstract}
Diagnostics is an important and challenging task of the structural analysis and condition assessment of historic masonry structures. However the interpretation of the results of the measurements, especially for buildings made from brick and stone, is to be more subjective than that for concrete structures. Therefore improvement of the reliability of the used techniques and finding better correlations between the test results and the mechanical properties of masonry has proven to be of great importance.

While several diagnostic procedures are commonly used in practice to test mechanical properties of masonry, e.g. Schmidt hammer test, analysis of drilled samples, penetration tests, etc. the results of these methods are considered reliable under laboratory conditions, several additional factors have to be taken into account in case of an in-situ application of these methods, that may largely affect the obtained results and conclusions. The results of the diagnostic procedures therefore need to be interpreted with a view to these environmental factors.

The paper focuses on the practical use of several test methods for historic masonries via a real case study. The presented case study attempts to demonstrate benefits from the combined application of Pendulum Schmidt Hammer, moisture meter and scanning electron microscopy.
\end{abstract}

Keywords: Historic masonries, Combined techniques, Hammer test, Moisture meter, Scanning electron microscopy, Non-destructive testing

\footnotetext{
${ }^{*}$ Corresponding Author
} 


\section{Introduction}

Preservation of historical buildings is an important task of cultural and architectural heritage. It is the common objective of scientists, artists, and engineers to find effective methods that allow maintenance of the conditions or restoration of these structures. In Hungary most of the building assets are more than 50 years old, and amongst the important cultural heritage buildings there are many from the $11^{\text {th }}-12^{\text {th }}$ century as well. Harmful environmental and other damaging effects let their marks on these structures throughout the years and centuries.

When a historical building is renovated, several factors have to be taken into account, like as the actual condition of the site, environment, construction of the building, its functional use, static condition, energy efficiency, economic factors, etc. Many times the function of the building is changed (e.g. when a hotel is converted into an office building). This new function might raise new challenges, especially when a building is conserved as a part of national cultural heritage, but generally in all the other cases. The consistency studies are of high importance, and each case has to be treated separately. Therefore, besides the indispensable destructive diagnostic test methods, the knowledge supplied by the non-destructive techniques contributes considerably to plan proper renovation measures.

The most effective destructive tests are those carried out on drilled samples removed from the structure. Mechanical properties like elastic modulus, compressive or flexural strength are necessary for structural analysis therefore the sampling by drilling usually cannot be avoided, however the number of drillings should be reduced by using additionally semi- and non-destructive methods [1].

Methods like video endoscopy, elemental analysis methods, X-ray and neutron diffraction, Scanning Electron Microscopy (SEM) etc. are considered specific semidestructive testing methods. These methods require only small sample volume/mass to be taken, therefore these examinations will produce only minimal damage on the building. Georadar, microwave methods, surface hammer test, infrared thermography, moisture measurements, etc. are considered entirely Non-Destructive Testing (NDT) methods. If several factors affecting the measurements are to be taken into account, there is a benefit from results obtained by the combined application of various semi- and non-destructive test methods [2].

In this paper a combined examination technique is presented, where the following equipment was used: pendulum hammer, moisture meter device and SEM.

Rebound hammer test is a commonly used NDT method. Basically European standards are defined for concrete structures, however proper correlation between rebound and compressive strength has to be developed for masonries (mainly brickwork) [3]. Monitoring the moisture content in case of brickwork and stonework buildings is of great importance for several reasons. Moisture is a primary deteriorating factor, especially in the case of external, non-protected walls. The high levels of moisture content may indicate the damaged state of the used material, in some cases the lower quality of the used materials (especially of the mortar). Moisture content initiate further damage mechanisms, like chemical and biological processes, cracking, fungal attack, etc. [4]. 
However it is difficult to find linear correlation between moisture content and the deterioration process of buildings. The so-called 'humidity paradox' defines this difficulty [5].

According to experience obtained from real case studies the combination of these techniques - surface hammer test, moisture meter test and SEM - gave reliable results on the damage level of the studied building, which was in good correlation with examinations carried out on drilled samples.

\section{Survey}

The first step of a survey is the simplest, but of a great importance: visual survey, which is indispensable in every case. Making a damage map at the site, as an in situ examination, shows the damped areas, cracks, spalls and other damages, and indicates the critical macroscopic areas.

The next step is determining the parameters of the load bearing structure, like bearing walls, arches, slabs. This step is also of high importance, especially in case of lacking an original plan. Masonries could have been made in various ways; therefore construction parameters are important to be defined. At the basis of the layout stay the measured length, width, thickness, and the determination of the construction material. Important details are the time of construction, and the locality. Depending on these parameters structural characteristics and mechanical properties (strength) can be estimated.

The survey has to be carried out by an experienced engineer; the expertise of the surveyor affects the results of the examination, and the choice of the diagnostic method [5].

\section{Sample size determination}

During the planned diagnostic process, even in case of a 'rough field', striving for accuracy is necessary. However the correlation between the number of samples and the accuracy of the results is not directly proportional. Typical problem, that the number of the consisting elements of a wall is large. It is impossible to analyze each brick and mortar layer separately; this procedure would be illogically expensive, and timeconsuming.

Statistically, the determination of the taken sample size (number of sampling points) is rather simple. For instance if the load-bearing wall is $38 \mathrm{~cm}$ wide, $3.0 \mathrm{~m}$ high and $15.0 \mathrm{~m}$ long, is made of brick, there are approximately 5400 bricks in the wall (assuming 12 bricks in 1 layer, 1 layer $\sim 10 \mathrm{~cm}$ high, joint with mortar, Fig. 1). The number of the bricks is the population

$$
n=\frac{z^{2} x p(1-p) / e^{2}}{1+z^{2} 2 x p(1-p) / e^{2} N},
$$


where $N$ is the population size; $e$ is the standard error; $p$ is the population proportion; $z$ is the $\mathrm{z}$-score.

The z-score is based on the chosen confidence level, which is the level of certainty and helps to estimate the true population value [6]. The correlation between confidence level and z-score is shown in Table I.

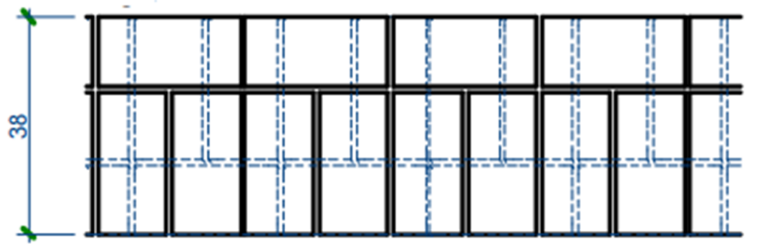

Fig. 1. One and a half bricks thick wall

Table I

To find the z-score

\begin{tabular}{|c|c|}
\hline Desired Confidence Level & z-score \\
\hline $80 \%$ & 1.28 \\
$85 \%$ & 1.44 \\
$90 \%$ & 1.65 \\
$95 \%$ & 1.96 \\
$99 \%$ & 2.58 \\
\hline
\end{tabular}

Sample size $(n)$ can be determined by using Eq. (1). In this formula population size is the total number of bricks in the wall (5400). The standard error is chosen to be $10 \%$. If the standard error is raised, the size of sample decreases, therefore this rate must be optimized. The confidence level is chosen to be $95 \%$. The result is the sample size, $n=95$.

In practice the determined (calculated) sample size is unrealistic, and proves to be too high; therefore accidental and stratified sampling must be used. On closer examination the number of sampling is huge. Using only one method, for example the drilled sample analysis, the damage of the structure is not acceptable. Available NDT methods help to increase the number of measures with simultaneous decreasing of number of destructive test sampling.

\section{Materials and methods}

The diagnosed building was a hotel in Székesfehérvár in Hungary, today it is out of use (Fig. 2). It was built in about 1820, but some parts of the building were constructed out of mediaeval building material. Load-bearing structures (walls, arches) were built by using conventional construction technics and traditional building material. 


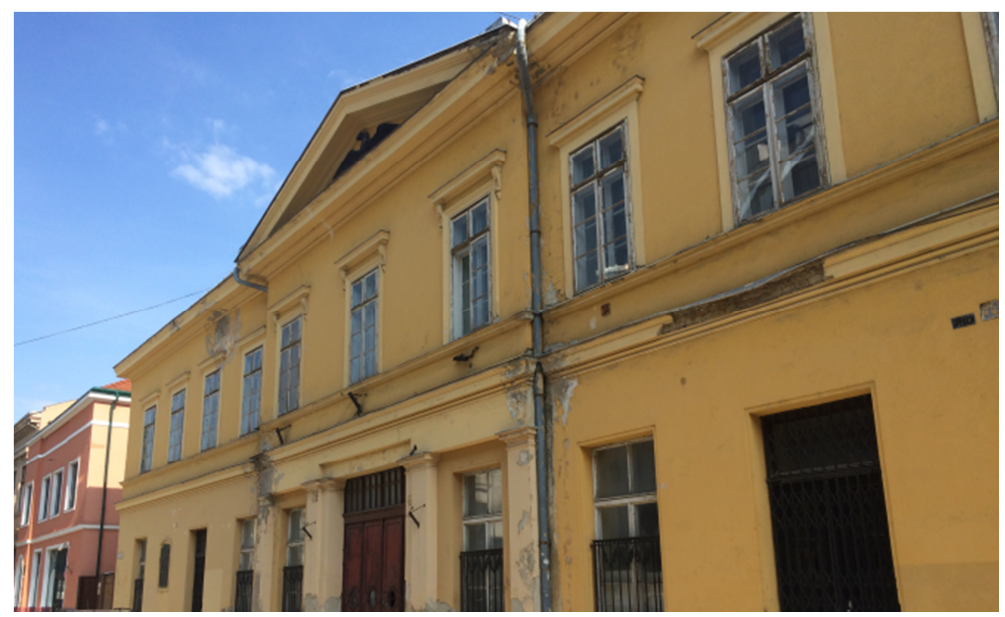

Fig. 2. Hotel Fekete Sas (Source: Author)

In the present case study, the main type of NDT methods used was hammer test and moisture test. The number of specimens taken by using destructive methods was limited, because of the cultural heritage status of the building. The tested structures were brickwork walls with lime based mortar binder, in some points of the walls with stone masonry units. Using hammer test only brick units were tested, because the compressive strength of stones is much higher compared to bricks and the number of stones was negligible. The examination of the strength of the stones was carried out as additional testing method; however the results were not applied in this research.

\section{Rebound hammer test}

Determination of compressive strength for load bearing structures is one of the most important tests that have to be performed. As for partition walls, the load derives only from the unladen weight. Usually, the most common problem of these types of walls is the deterioration due to cracks, spalls, efflorescence, and humidity [5].

For brickworks, the most commonly used in-situ, NDT method is pendulum hammer test, used to determine the compressive strength of bricks. The hammer has an arbitrary scale ranging from 0 to 200. Data for masonries is mainly ranging from 50 to 90 . The working mechanism of this type of hammer is similar to an ordinary Schmidt hammer. It works with the pendulum system; therefore it must not be loaded on the test surface. The mechanism of pendulum hammer is based on measuring the rebound of an anvil that impacts a plunger in contact with a concrete surface.

Pendulum hammer is designed to measure the elastic properties or strength of softer materials. Like lightweight concrete, gypsum boards, fresh concrete and the mortar of joints in brickwork. The test is usually used to measure the overall quality of masonry. It is proved, that the higher rebound number means higher masonry compressive strength. 
Hammer test is very sensitive to local properties. Thus, a series of measurements have to be performed in a limited area around the same point (for example chosen one brick in the masonry). The average of them gives a representative value for the local, restricted area.

EN 12504-2 requires a minimum of 9 rebound values for calculating the median for concrete [5], Active Standard Test Method (ASTM) C 805 for rebound number of hardened concrete requires 10 rebound numbers to be taken for one test. The ideal number of impacts must be specified from 3 to 10 on one element [7].

In the present case study the hammer test (using machine Schmidt OS-120PT) was conducted in at least 10 chosen locations on each floor. At these designated places 5 bricks were chosen, all of which were tested three times. Fig. 3 shows a typical testing location. Compressive strength was estimated from the rebound number, using the special conversion curves based on the user manual [7]. Results are explained in the paragraph 7.

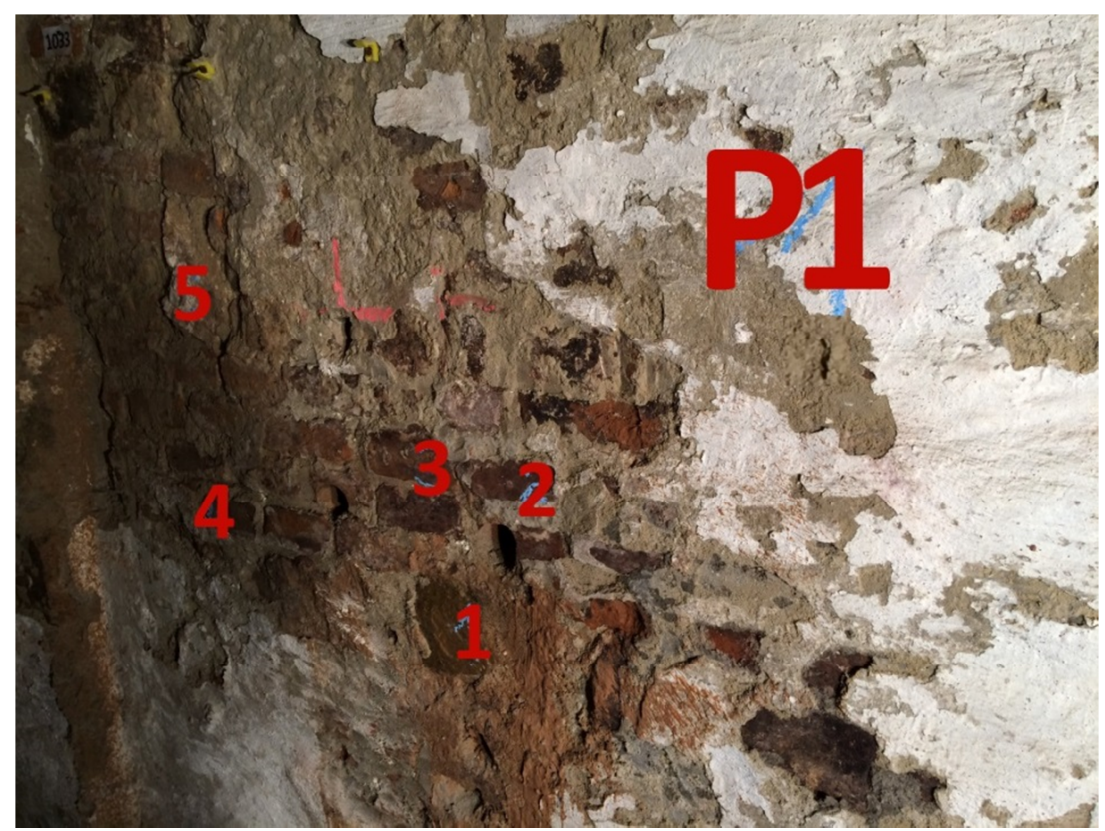

Fig. 3. P1 labeled location - cellar wall with 2 drilled sampling places and 5 labeled bricks for rebound hammer and moisture meter test (Source: Author)

\section{Moisture meter test}

According to recently published papers there is a correlation between moisture content and the strength of materials, nevertheless an exact correlation has not been determined yet. 
In practice generally higher moisture level indicates lower strength, especially in the case of surface hardness. Moisture meter tests show the condition of structures, and help to evaluate the results of other diagnostic procedures, in order to get a more precise picture of the wall condition. Therefore moisture meter usually is combined with rebound hammer test.

Measure mode of protimeters is based on electric conductivity. The resistance-type moisture meter devices have two functions: surface and sub-surface measurement. Surface reading mode (two-pin method) as its name indicates, measures the moisture level on the surface. Measure mode readings are precise and specific to the immediate area of contact of the electrodes. Sub-surface reading mode (deep wall probe method) helps to determine the sub-surface moisture of the material. Using these method two (10 cm deep) holes must be drilled into the material, which the external auxiliary port of the device is pushed to be able to determine the moisture content [8].

The moisture content of the material is displayed in mass percent $(\mathrm{m} \%)$ and a condition category is assigned to the measured value (dry, moist, wet, soaked watery, waterlogged) [9]. It is important to know that there might be some correlation between high moisture level and some common building material damage phenomena, having negative effect on the condition of the structure.

One of the most important phenomena is rising damp that causes the majority of the problems in case of historical buildings. Old buildings are usually un-insulated against water; therefore the capillary condensation in the walls conduces to material deterioration. This problem can be easily detected by making a 'moisture profile' of the studied wall. The moisture profile of the walls is measured vertically at regular intervals. If the moisture profile of the wall shows high moisture content on the lower, and low moisture content on the higher parts of the wall by showing a sudden 'cut-off' in the moisture content, rising damp phenomena has occurred. This sudden 'cut-off' is usually at about $1.5 \mathrm{~m}$ high [8].

The height of the damp in the wall - amongst other factors - depends on pore size and pore size distribution. Smaller pores help capillary condensation and result into the highest possible level of the rising damp. The effect of the pore size can be visualized by SEM, which is shown in Fig. 4 (See paragraph 7).
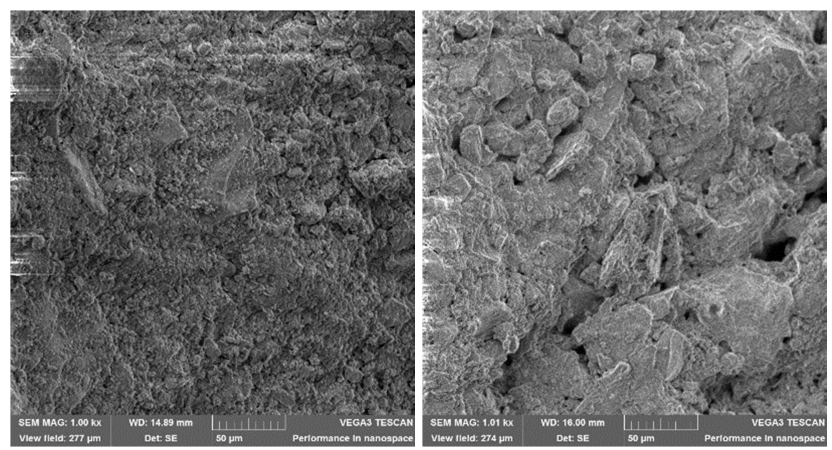

Fig. 4. Cellar wall brick and first floor brick sample analysis with SEM (1000x magnification) (Source: Author) 
Besides rising damp, high moisture level can cause several other problems too, like 'expansive crystallization effects', which is explained by the tendency of some salts to expand in volume when they crystallize. Presence of salts causes surrosion, which results in strength decrease, therefore damage of materials. Besides porosity, salt content can also be analyzed by SEM [4].

In the analyzed building (Hotel Fekete Sas), the cellar walls were found critically wet, and the deep wall probe method shown 90-100 $\mathrm{m} \%$ moisture content.

Because of high moisture content the possibility of rising damp was considered, but at the 'moisture profile' did not prove the phenomenon. The main reason was the lack of the sudden 'cut-off' at the height of $1.5 \mathrm{~m}$. The curve and the results of the tests are shown in Table II and in Fig 5. High moisture content derives from unheated rooms, thickness of the walls (more than $1.0 \mathrm{~m}$ ) and un-insulated structures.

Table II

Surface moisture meter test results of the ground floor wall

\begin{tabular}{|c|c|c|c|c|c|c|c|c|}
\hline \multirow{2}{*}{ 总 } & \multicolumn{2}{|c|}{ N1 } & \multicolumn{2}{|c|}{ N2 } & \multicolumn{2}{|c|}{ N3 } & \multicolumn{2}{|c|}{ N4 } \\
\hline & $\begin{array}{l}\text { brick } \\
(\mathrm{m} \%)\end{array}$ & $\begin{array}{c}\text { mortar } \\
(\mathrm{m} \%)\end{array}$ & $\begin{array}{l}\text { brick } \\
(\mathrm{m} \%)\end{array}$ & $\begin{array}{c}\text { mortar } \\
(\mathrm{m} \%)\end{array}$ & $\begin{array}{l}\text { brick } \\
(\mathrm{m} \%)\end{array}$ & $\begin{array}{c}\text { mortar } \\
(\mathrm{m} \%)\end{array}$ & $\begin{array}{l}\text { brick } \\
(\mathrm{m} \%)\end{array}$ & $\begin{array}{c}\text { mortar } \\
(\mathrm{m} \%)\end{array}$ \\
\hline 0.2 & 13.8 & 70.3 & no data & no data & no data & no data & 16.6 & 19.5 \\
\hline 0.5 & no data & no data & 20.9 & 47.9 & 16.4 & 46.6 & no data & no data \\
\hline 1 & 19 & 20.3 & 32.1 & 29.9 & 21 & 46.2 & 20.5 & 23.1 \\
\hline 1.8 & 19.9 & 20.9 & 28.8 & 46 & 41.8 & 70.3 & 22.8 & 20.5 \\
\hline
\end{tabular}

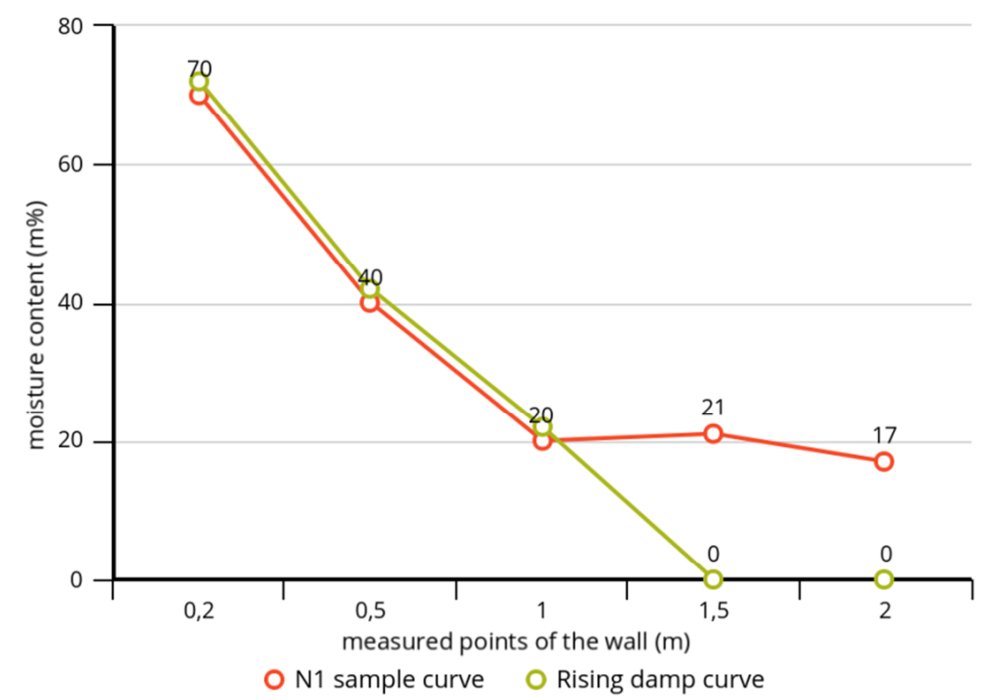

Fig. 5. Moisture content trend for N1 sample and the typical rising damp sample 


\section{Scanning electron microscopy measurements}

The SEM used was a VEGA 3S type one, with a secondary electron detector. The proper adjustment of the microscopy was necessary to analyze the specimens. The electron beam of only between $5-11 \mathrm{kV}$ could be used. The analyzed samples were bombarded with electrons because there were not conductors [4].

Two SEM pictures were taken at 200-500x and s 3000-5000x magnifications. From the SEM pictures conclusions about the condition of the walls could be drawn. In the cellar wall samples mycelium (Fig. 6.) and salts were identified. On the surface of the samples affected by sulphate, granular coarse crystals ('coralliferous') were seen (Fig. 7) [10].

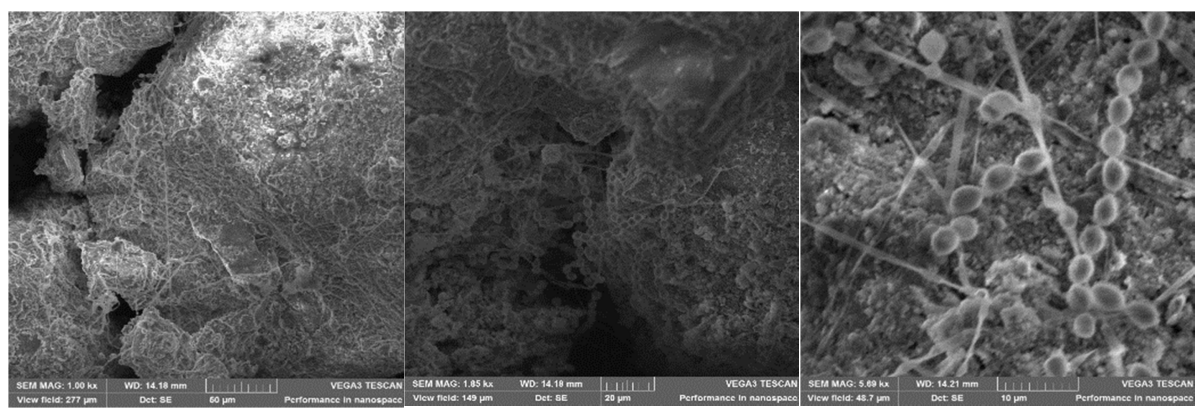

Fig. 6. P4 (mortar) sample analyzed with SEM (mycelium, conidia) (Source: Author)

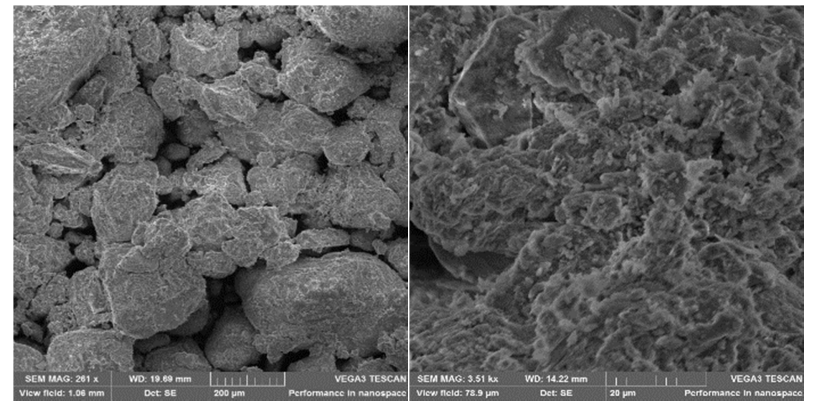

Fig. 7. P3 (mortar) sample analyzed with SEM (sulphate) (Source:Author)

In case of the mortar samples the degree of porosity of the different samples was highly variable. Some of the samples were highly porous, friable, as if their compressive strength were zero. Brick and mortar only partly worked together, and as a consequence, strain was larger in the structure. 


\section{Results, observations and conclusions}

Results of rebound hammer and drilled sample compressive strength tests are shown in Table III. From the results presented it is clear that there is good correlation between the results obtained by the two tests.

\section{Table III}

Compressive strength collating

\begin{tabular}{|c|c|c|c|c|c|}
\hline \multirow{2}{*}{ 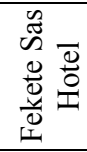 } & \multicolumn{2}{|c|}{ Measured of the drill sample } & \multicolumn{2}{|c|}{$\begin{array}{c}\text { Calculate from rebound } \\
\text { numbers }\end{array}$} & \multirow{2}{*}{$\begin{array}{c}\text { Number of } \\
\text { hammer } \\
\text { test } \\
\text { position }\end{array}$} \\
\hline & $\begin{array}{c}\text { Drilled } \\
\text { sample sign }\end{array}$ & $\begin{array}{c}\text { Compressive } \\
\text { strength }\left(\mathrm{N} / \mathrm{mm}^{2}\right)\end{array}$ & $\begin{array}{c}f_{c} / \text { cylinder/ } \\
\left(\mathrm{N} / \mathrm{mm}^{2}\right)\end{array}$ & $\begin{array}{l}f_{c} / \text { cube/ } \\
\left(\mathrm{N} / \mathrm{mm}^{2}\right)\end{array}$ & \\
\hline \multirow{5}{*}{$\begin{array}{l}\frac{n}{\pi} \\
\frac{3}{3} \\
\bar{\Xi} \\
\overline{0}\end{array}$} & $\mathrm{P} 1 / 1$ & 10.44 & \multirow[b]{5}{*}{8.76} & \multirow[b]{5}{*}{11.03} & \multirow[b]{5}{*}{50} \\
\hline & $\mathrm{P} 1 / 2$ & 7.87 & & & \\
\hline & $\mathrm{P} 2 / 1$ & 6.75 & & & \\
\hline & $\mathrm{P} 3 / 2$ & 10.10 & & & \\
\hline & Average: & 8.79 & & & \\
\hline \multirow{4}{*}{ 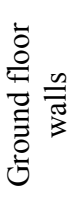 } & $\mathrm{L} 1 / 1$ & 8.75 & \multirow[b]{4}{*}{6.43} & \multirow[b]{4}{*}{8.09} & \multirow[b]{4}{*}{60} \\
\hline & $\mathrm{L} 1 / 2$ & 6.50 & & & \\
\hline & L2 & 4.58 & & & \\
\hline & Average: & 6.61 & & & \\
\hline \multirow{6}{*}{ 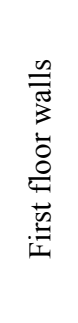 } & EM1/1 & 8.43 & \multirow[b]{6}{*}{7.25} & \multirow[b]{6}{*}{9.13} & \multirow[b]{6}{*}{45} \\
\hline & EM1/2 & 7.28 & & & \\
\hline & EM1/3 & 8.31 & & & \\
\hline & EM21 & 7.03 & & & \\
\hline & EM $2 / 2$ & 9.21 & & & \\
\hline & Average: & 8.05 & & & \\
\hline
\end{tabular}

Rebound hammer test was well applicable for the determination of brick compressive strength. However, it is important to note that the special measure points, for example mixed walls (made of stone and brick), inner holes etc. have to be left out from rebound test calculations. In spite of the usefulness of the NDT methods the destructive drilled sample tests could not be totally avoided, they had to be performed for the validation of the NDT tests results. The number of drilled samples was kept as low as possible, but it can affirm that the exact number of drilling places depend always on the structure and needs to be determined by taking into account all the existing environmental, static, historical, material conditions in order to minimize the damaging of cultural heritage buildings, but not compromise the validity of the results. 
Drilled samples had to be taken from at least 3 places (per floor) to gain the adequate results. The taken samples were analyzed by compressive strength test carried out on $50 \mathrm{~mm}$ diameter cores (Fig. 8).

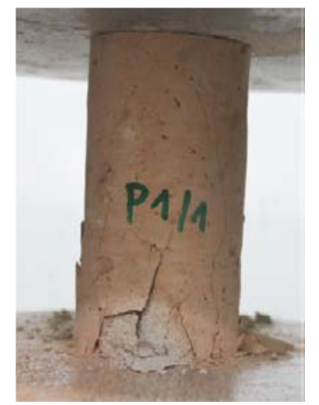

Fig. 8. P1/1 drilled sample test with SERCOMP 7 type (50-C7022) universal testing machine (Source: Author)

The walls consisted only of one type of brick it was possible to determine the compressive strength of brick elements by using the rebound hammer test without the need for taking drilled samples. The combined use of NDT methods and drilled sample compressive strength test gave more exact results.

Moisture meter test helped to refine the results of hammer test, and made possible building a condition profile for the walls. All these results were completed by using scanning electron microscope. Using SEM it became possible to determine special properties, like porosity, capillary condensation, salt content, harmful micro organizations, micro cracks.

The combined use of these three NDT methods made possible to determine the condition of the walls and compressive strength of the brick elements.

The applied test methods contributed to the realistic condition assessment of the building and helped to develop for repairing and strengthening.

\section{Acknowledgement}

This paper was supported by the ÚNKP-18-3-IV-PTE-203 New National Excellence Program of the Ministry of Human Capacities.

\section{Open Access statement}

This is an open-access article distributed under the terms of the Creative Commons Attribution 4.0 International License (https://creativecommons.org/licenses/by/4.0/), which permits unrestricted use, distribution, and reproduction in any medium, provided the original author and source are credited, a link to the CC License is provided, and changes - if any - are indicated. (SID_1) 


\section{References}

[1] Orban Z. Assessment and lifetime expectancy of historical masonry arch bridges, Pollack Periodica, Vol. 9, No. 1, 2014, pp. 7-16.

[2] Breysse D. (Ed.) Non-destructive assessment of concrete structures: Reliability and limits of single and combined techniques, State-of-the-art reports of the RILEM Technical Committee 207-INR, 2012.

[3] Török B., Len A., Orban Z. Salt content analysis of historic masonries with SEM, Pollack Periodica, Vol. 9, No. 1, 2017, pp. 7-16.

[4] Shaw P., Xu A. Assessment of the deterioration of concrete in nuclear power plants causes, effects and investigative methods, NDTnet, Vol. 3, No. 2, 1998.

[5] Johnson L. How to calculate confidence levels, Sciencing, https://sciencing.com/calculateconfidence-levels-2844.html, (last visited 25 April 2018).

[6] SCHMIDT OS-120 Operating introduction book (Part Number: 82031002E ver 02 2016) 2017.

[7] Protimeter Mini ${ }^{\circledR}$ Sensing User Instructions, 2004.

[8] Rirsch E., Zhang Z. Rising damp in masonry walls and the importance of mortar properties, Construction and Building Materials, Vol. 24, No. 10, 2010, pp. 1815-1820.

[9] Lubelli B., van Hees R. P. J. Effectiveness of crystallization inhibitors in preventing salt damage in building materials, Journal of Cultural Heritage, Vol. 8, No. 3, 2007, pp. 223-234.

[10] Gentilini C., Franzoni E., Bandini S., Nobile L. Effect of salt crystallisation on the shear behaviour of masonry walls: An experimental study, Construction and Building Materials, Vol. 37, 2012, pp. 181-189. 